\title{
Evaluation of Running Conditions for SSCP Analysis: Application of SSCP for Detection of Point Mutations in the LDL Receptor Gene
}

\author{
Trond P. Leren, ${ }^{1}$ Kari Solberg, ${ }^{1}$ Olaug K. Rødningen, ${ }^{1}$ Leiv Ose, ${ }^{2}$ Serena Tonstad, ${ }^{2}$ \\ and Kåre Berg 1,3
}

\begin{abstract}
${ }^{1}$ Department of Medical Genetics, Ullevål University Hospital, ${ }^{2}$ Lipid Clinic, Rikshospitalet, and ${ }^{3}$ Institute of Medical Genetics, University of Oslo, Oslo, Norway
\end{abstract}

We have performed analyses of single-strand conformation polymorphisms (SSCP) of the promoter region and the translated parts of the 18 exons of the low-density lipoprotein receptor (LDLR) gene. DNA from 20 unrelated familial hypercholesterolemia (FH) patients was studied. Four different running conditions were used for the nondenaturing gel electrophoresis to systematically evaluate how differences in the running conditions affect the sensitivity of the assay. These conditions were $15 \mathrm{~W}, 40 \mathrm{~W}$, and $50 \mathrm{~W}$ in the absence of glycerol, and $50 \mathrm{~W}$ in the presence of $10 \%$ glycerol. SSCP analyses of the 18 PCR fragments for the 20 subjects revealed a total of 46 genotypes at 15 $W, 45$ at $50 \mathrm{~W}, 42$ at $40 \mathrm{~W}$, and 41 at $50 \mathrm{~W}$ with $10 \%$ glycerol. A total of 53 different genotypes were observed when the results of the four conditions were considered together. Assuming that the four conditions together detected $100 \%$ of the different genotypes, the sensitivity of the four individual conditions ranged between $87 \%(15 \mathrm{~W}$ ) and $77 \%$ (50 W with $10 \%$ glycerol). There were marked differences among the different running conditions to detect abnormal SSCP patterns of individual exons. Therefore, different conditions should be used for the different exons of the LDLR gene.
$\Delta$ single-strand conformation polymorphisms (SSCP) ${ }^{(1-3)}$ has become an important tool for detecting point mutations underlying genetic diseases. This technique is based on a single point mutation altering the conformation of single-stranded DNA (ssDNA). Altered conformation affects the migration of ssDNA that can be detected as abnormal bands on a nondenaturing gel. The mutations underlying the abnormal bands are then characterized by DNA sequencing.

The sensitivity of SSCP in detecting point mutations is dependent on several factors. These include the length of the fragment, the extent of cross-linking concentration of acrylamide, the presence of glycerol, the temperature during electrophoresis, and buffer concentration. ${ }^{(3,4)}$. Thus, it is of great importance to finetune the SSCP assay.

The most important factor in this respect is the temperature during electrophoresis. This is because the formation of intrastrand bonds, and thereby the conformation of ssDNA, is temperature dependent. The temperature during electrophoresis can be altered by altering the ambient temperature or by altering the wattage. In addition to temperature, the presence of glycerol in the gel may affect the conformation of ssDNA significantly. ${ }^{(1,3)}$

Familial hypercholesterolemia (FH) is an autosomal dominant disease characterized by hypercholesterolemia and premature coronary heart disease. ${ }^{(5)} \mathrm{FH}$ is caused by a mutation in the gene en- coding the low-density lipoprotein receptor (LDLR). The LDLR gene consists of 18 exons, the translated parts of which range from 78 to $381 \mathrm{bp} .^{(6,7)}$ Thus, the gene lends itself to amplification of individual exons by PCR and analyses of SSCP.

In this study we have established the conditions for amplification of the promoter region and the translated parts of the 18 exons of the LDLR gene. Subsequently, SSCP analyses were performed of these PCR fragments from 20 unrelated FH patients. Four different conditions were used for the nondenaturing gel electrophoresis to systematically evaluate how differences in the running conditions affect the sensitivity of the assay.

\section{MATERIALS AND METHODS}

\section{Subjects}

Twenty unrelated, Norwegian FH subjects were included in the study; 18 were heterozygotes, and 2 were homozygotes. FH was diagnosed on a clinical basis according to the criteria of Goldstein and Brown. ${ }^{(5)}$ Haplotypes at the LDLR locus were constructed using the seven haplotype markers described by Rødningen et al. ${ }^{(8)}$ Hypercholesterolemia segregated with haplotypes at the LDLR locus in the families of all 20 subjects (data not shown). None of the subjects possessed the apoB 3500 mutation, ${ }^{(9)}$ as determined by the assay of Hansen et al. ${ }^{(10)}$ (data not shown). 


\section{Amplification of Individual Exons of the LDLR Gene}

The primers used to amplify individual exons from genomic DNA were those described by Leitersdorf et al. ${ }^{(11)}$ except from amplification of exons 1 and 18. A 343-bp fragment comprising exon 1 and the 5 '-flanking region to position -251 , was amplified using the primers SPPROM (5'-TGGAGTGGGAATCAGAGCTTCACGG-3') and SP91. ${ }^{(9)}$ A 173-bp fragment of exon 18 was amplified using the primers SP150 ${ }^{(9)}$ and SP2684 (5'-ATAAAACAAAGCTCTGGCAGGCAAT- $3^{\prime}$ ). The mixtures prepared for the PCRs contained 400 ng of DNA, 20 pmoles of each of the two exon-specific primers, $200 \mu \mathrm{M}$ dNTPs, $3.3 \mathrm{~nm}\left[{ }^{32} \mathrm{P}\right] \mathrm{dCTP}(3000 \mathrm{Ci} /$ mmole), and the buffer [ $10 \mathrm{~mm}$ Tris- $\mathrm{HCl}$, $1.5 \mathrm{~mm} \mathrm{MgCl}_{2}, 50 \mathrm{~mm} \mathrm{KCl}, 0.1 \mathrm{mg} / \mathrm{ml}$ of gelatin ( $\mathrm{pH} \mathrm{8.3)]} \mathrm{supplied} \mathrm{with} \mathrm{the} \mathrm{Taq}$ DNA polymerase purchased from Boehringer Mannheim (Mannheim, Germany). The reaction volume was $100 \mu \mathrm{l}$. A DNA Thermal Cycler (Perkin-Elmer Cetus, Norwalk, CT) was used for the PCRs. The conditions for amplification of individual exons were established and are shown in Table 1.

\section{Analysis of SSCP}

Eight microliters of the loading buffer (95\% formamide, $20 \mathrm{~mm}$ EDTA, 0.05\% Bromphenol blue, $0.05 \%$ xylene cyanol) was added to $2 \mu \mathrm{l}$ of radiolabeled PCR products and heated for $2 \mathrm{~min}$ at $94^{\circ} \mathrm{C}$. A $2-\mu l$ aliquot of this mixture was loaded into each well of a $6 \%$ nondenaturing sequencing gel (acrylamide/bisacrylamide, 100:1.5). The sequencing apparatus was a Sequi-gen Sequencing Cell (Bio-Rad, Richmond, CA). The PCR products from each individual were run under four different conditions in a cold room. These conditions were 15,40 , or $50 \mathrm{~W}$ in the absence of glycerol and 50 $\mathrm{W}$ in the presence of $10 \%$ glycerol. The electrophoreses were performed for approximately $1.5 \mathrm{hr}$ at 40 and at $50 \mathrm{~W}$ in the absence of glycerol. For the two other conditions the electrophoreses were performed for $\sim 3 \mathrm{hr}$. The gels were transferred to Whatman $3 \mathrm{MM}$ papers, dried, and autoradiographed for 5-7 days at $-80^{\circ} \mathrm{C}$.

\section{Evaluation of the SSCP Patterns}

All SSCP analyses were performed by one of us (K.S.). Each autoradiogram contained the analyses of one exon for the 20 subjects using one of the four different running conditions. The typing of the band patterns was performed as a two-step procedure. First, two of us (O.K.R. and T.P.L.) typed each running condition for all exons blindly with respect to the results obtained with the three other conditions. Thus, this typing would mimic the situation as if only one running condition were employed. Second, all four running conditions were considered together by three of us (K.S.,
O.K.R., and T.P.L.) when typing each exon for abnormal band patterns. This would represent the situation of employing four different running conditions to screen for mutations.

\section{RESULTS \\ Pilot Study}

Before the systematic SSCP analyses of the 18 exons were started, a pilot study was performed to determine the appropriateness of the four different running conditions that were subsequently used for the study. In the pilot study, three exons $(8,13$, and 14$)$ of the LDLR gene containing known mutations were amplified from the DNA of $20 \mathrm{FH}$ subjects. Exons 8 and 13 contain polymorphic $S t u \mathrm{I}^{(12)}$ and AvaII ${ }^{(13)}$ sites, respectively. These RFLPs had been analyzed by restriction cutting of amplified PCR fragments. The two patterns observed by SSCP analyses of exon 8 were in accordance with homozygosity or heterozygosity for the presence of the StuI cutting site. These patterns could easily be identified by any of the four conditions used for the gel electrophoresis. The three patterns observed by SSCP analyses of exon 13 were in accordance with the three genotypes of the AvalI RFLP. Although the three patterns of exon 13 could be identified by all four running conditions, $15 \mathrm{~W}$ was very much superior to the three others (data not shown). One subject who was heterozygous for a mis-

TABLE 1 Fragment Lengths of the Promoter Region and the Translated Parts of the 18 Exons the LDLR Gene and Conditions for the PCRs

\begin{tabular}{|c|c|c|c|c|c|c|c|c|c|c|c|c|c|c|c|c|c|c|}
\hline & \multicolumn{18}{|c|}{ Exon } \\
\hline & $\begin{array}{l}\text { promoter } \\
+1\end{array}$ & 2 & 3 & 4 & 5 & 6 & 7 & 8 & 9 & 10 & 11 & 12 & 13 & 14 & 15 & 16 & 17 & 18 \\
\hline Fragment length $^{a}$ & 343 & 173 & 173 & 431 & 173 & 173 & 170 & 176 & 222 & 278 & 169 & 190 & 192 & 203 & 221 & 128 & 208 & 173 \\
\hline \multicolumn{19}{|l|}{ Primers } \\
\hline $5^{\prime}$ & SPPROM $^{\mathrm{b}}$ & SP57 & SP59 & SP61 & SP62 & SP64 & SP66 & SP68 & SP70 & SP72 & SP74 & SP76 & SP78 & SP80 & SP82 & SP84 & SP86 & SP150 \\
\hline $3^{\prime}$ & SP91 & SP58 & SP60 & SP51 & SP63 & SP65 & SP67 & SP69 & SP71 & SP73 & SP75 & SP77 & SP79 & SP81 & SP83 & SP85 & SP87 & $2684^{\mathrm{b}}$ \\
\hline \multicolumn{19}{|l|}{ Taq DNA poly- } \\
\hline merase (units) & 1.5 & 2 & 1.5 & 1 & 1 & 0.75 & 1 & 1 & 1 & 1 & 1 & 1 & 1 & 1.25 & 1 & 1 & 1 & 1.5 \\
\hline \multicolumn{19}{|l|}{$\begin{array}{c}\text { Thermal cycling } \\
\text { denaturation }\end{array}$} \\
\hline$\left({ }^{\circ} \mathrm{C}\right)$ & 94 & 94 & 94 & 95 & 94 & 94 & 94 & 94 & 94 & 94 & 94 & 94 & 94 & 94 & 94 & 94 & 94 & 94 \\
\hline annealing $\left({ }^{\circ} \mathrm{C}\right)$ & 48 & 53 & 50 & 62 & 58 & 45 & 58 & 49 & 55 & 55 & 50 & 50 & 50 & 55 & 50 & 50 & 50 & 50 \\
\hline extension $\left({ }^{\circ} \mathrm{C}\right)$ & 72 & 72 & 72 & 72 & 72 & 72 & 72 & 72 & 72 & 72 & 72 & 72 & 72 & 72 & 72 & 72 & 72 & 72 \\
\hline
\end{tabular}

All thermal cyclings consisted of 25 cycles. They were preceded by initial denaturation for 7 min at $94^{\circ} \mathrm{C}$ and completed by terminal extension for $10 \mathrm{~min}$ at $72^{\circ} \mathrm{C}$.

${ }^{\text {a }}$ Fragment lengths (in bp) include the two 25-bp exon-flanking oligonucleotides.

b Primer sequences are given in Materials and Methods. All other primer sequences are from Leitersdorf et al. ${ }^{(9)}$ 
sense mutation in codon 664 of exon 14 as determined by restriction cutting with PstI, ${ }^{(14)}$ possessed a SSCP pattern different from those who were homozygous for the wild-type allele. The abnormal pattern in this subject could be identified using any of the four conditions for the gel electrophoresis.

This pilot study told us that we were able to detect all three known mutations and the resulting seven genotypes present in this group of patients. Furthermore, the finding that some genotypes were much easier to detect by one condition than others indicated that running the gel under different conditions would increase the overall sensitivity of the assay.

\section{Applying Single Running Conditions for Gel Electrophoresis}

The promoter region and each of the 18 exons of the LDLR gene amplified from $20 \mathrm{FH}$ subjects were examined by SSCP analysis using the four different conditions for the gel electrophoresis. Each condition was analyzed blindly with respect to the results obtained with the three other conditions. The number of different patterns for the four different conditions are shown in Table 2.

There were relatively large differences in the number of different SSCP patterns observed for each exon using the different running conditions. These ranged from 1 (exons $1,6,9,17$ ) to 5 (exons 10-12). No additional information was obtained for seven of the exons (exons 1 , $6-9,17,18)$ using four different conditions for the gel electrophoresis as compared with only one. However, for the other 11 exons there was a marked difference in the sensitivity of the different conditions to detect abnormal patterns. This was most prominent for exon 2, where gel electrophoresis at $40 \mathrm{~W}$ revealed the same pattern in all 20 subjects; gel electrophoresis at $50 \mathrm{~W}$ in the presence of $10 \%$ glycerol, however, revealed four different patterns (Fig. 1). Thus, three additional patterns were observed at $50 \mathrm{~W}$ in the presence of $10 \%$ glycerol as compared with the pattern observed at $40 \mathrm{~W}$. For exons 4, 10, 11, 14, and 15 , the condition with the highest number of patterns had two more patterns than the condition with the lowest number.

The different sensitivities of the running conditions to detect mutations are illustrated in Figure 1. Whereas, $15 \mathrm{~W}$ detects three of four different genotypes in exon 2, it detects only one of three genotypes in exon 4 . Furthermore, $50 \mathrm{~W}$ in the presence of $10 \%$ glycerol detects all four genotypes of exon 2 but only two of the three in exon 4.

\section{Applying Four Running Conditions for Gel Electrophoresis}

Except for exons 11 and 14, the number of patterns observed with the running condition that had the highest number of patterns was identical to the number observed when the four conditions were considered together. For exons 11 and 14 , the condition with the highest number of patterns failed to identify an abnormal band pattern that could be detected with one of the other conditions. Assuming that the number of different patterns represents the number of differ-

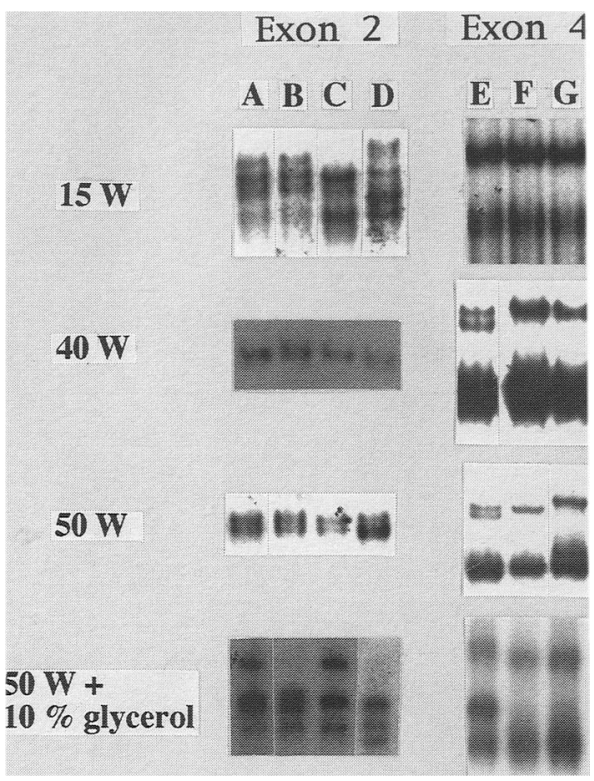

FICURE 1 SSCP analyses of exons 2 and 4 of the LDLR gene were performed using four different running conditions for the nondenaturing gel electrophoresis. These conditions were 15,40 , and $50 \mathrm{~W}$ in the absence of glycerol and $50 \mathrm{~W}$ in the presence of $10 \%$ glycerol. The SSCP patterns of subjects $A$ and $B$ were identical for three of the conditions but were different at $50 \mathrm{~W}$ in the presence of glycerol. The SSCP patterns of subjects $B-D$ were identical at $40 \mathrm{~W}$ but could be separated using the three other conditions. The SSCP patterns of subjects $E$ and $F$ were identical at $15 \mathrm{~W}$. Subject $E$ was clearly different from $F$ and $G$ with the three other conditions. Subjects $F$ and $G$ were only different at $50 \mathrm{~W}$ in the absence of glycerol.

ent genotypes, analyses of SSCP of all 18 PCR fragments for the 20 subjects revealed a total of 46 genotypes at $15 \mathrm{~W}, 45$ at $50 \mathrm{~W}, 42$ at $40 \mathrm{~W}, 41$ at $50 \mathrm{~W}$ with $10 \%$

TABLE 2 Observed SSCP Patterns

Exon

\begin{tabular}{|c|c|c|c|c|c|c|c|c|c|c|c|c|c|c|c|c|c|c|}
\hline Condition & $\begin{array}{l}\text { promoter } \\
+1\end{array}$ & 2 & 3 & 4 & 5 & 6 & 7 & 8 & 9 & 10 & 11 & 12 & 13 & 14 & 15 & 16 & 17 & 18 \\
\hline $15 \mathrm{~W}$ & 1 & 3 & 4 & 1 & 1 & 1 & 2 & 2 & 1 & 5 & 5 & 5 & 3 & 4 & 3 & 1 & 1 & 3 \\
\hline $40 \mathrm{~W}$ & 1 & 1 & 4 & 2 & 2 & 1 & 2 & 2 & 1 & 4 & 5 & 5 & 3 & 3 & 1 & 1 & 1 & 3 \\
\hline $50 \mathrm{~W}$ & 1 & 3 & 4 & 3 & 1 & 1 & 2 & 2 & 1 & 5 & 5 & 4 & 3 & 3 & 1 & 2 & 1 & 3 \\
\hline $50 W+10 \%$ & & & & & & & & & & & & & & & & & & \\
\hline glycerol & 1 & 4 & 3 & 2 & 1 & 1 & 2 & 2 & 1 & 3 & 3 & 5 & 3 & 2 & 3 & 1 & 1 & 3 \\
\hline Total & 1 & 4 & 4 & 3 & 2 & 1 & 2 & 2 & 1 & 5 & 6 & 5 & 3 & 5 & 3 & 2 & 1 & 3 \\
\hline
\end{tabular}

Number of different SSCP patterns observed for analyses of the promoter region and the 18 exons of the LDLR gene from $20 \mathrm{FH}$ subjects using four different conditions for the gel electrophoresis. These conditions were 15,40 , and $50 \mathrm{~W}$ in the absence of glycerol and $50 \mathrm{~W}$ in the presence of $10 \%$ glycerol. The number of different SSCP patterns shown for each condition is the number observed when the investigators were blinded with respect to the band pattern obtained with the three other running conditions. The total number of patterns is the number observed when all four conditions were considered together. 
glycerol, and 53 genotypes when all four conditions were considered together (Table 2).

Assuming that the sensitivity of the four conditions together to detect mutations is $100 \%$ (i.e., 53 different genotypes), the sensitivity of each of the four conditions is $87 \%(15 \mathrm{~W}), 85 \%(50 \mathrm{~W})$, $79 \%(40 \mathrm{~W})$, and $77 \%(50 \mathrm{~W}$ with $10 \%$ glycerol). Consequently, the use of four different running conditions as opposed to only one increases the sensitivity of the assay by $15 \%(15 \mathrm{~W})$ to $30 \%(50 \mathrm{~W}$ with $10 \%$ glycerol).

\section{DISCUSSION}

In this study we have evaluated how different conditions for gel electrophoresis affect analysis of SSCP of the LDLR gene. All gel electrophoreses were run in a cold room to standardize the assay. Running the electrophoreses at room temperature could seriously reduce the reproducibility of the assay as the ambient temperature might exhibit seasonal variations. This is definitely true for most laboratories in Norway.

Regarding the sensitivity of the assay, the seven genotypes analyzed in our pilot study were all correctly identified by analysis of SSCP. This agrees well with the reported data of the sensitivity of SSCP being in the range of $89-100 \%$. $^{(3)}$ The higher figure applies to fragments $100-300 \mathrm{bp}$ long, and the lower figure applies to fragments $300-450 \mathrm{bp}$ long. As all our fragments except one are $<280$ $\mathrm{bp}$, it suggests that the sensitivity of SSCP in detecting point mutations in exons of the LDLR gene must be relatively high. Thus, when four different running conditions are used for the gel electrophoresis, it is plausible that our assumption of a sensititivity of $100 \%$ is valid.

Our findings that the overall sensitivity increases by increasing the number of conditions for the gel electrophoresis agrees with those of others. ${ }^{(1,15)}$ However, employing several running conditions for each PCR fragment is time consuming and must be weighed against the increased sensitivity. The data reported in this paper indicate that using four different running conditions as opposed to only one increases the sensitivity by 15 $30 \%$. However, some caution must be exercised in generalizing from these data because they apply in principle only to the specific mutations in our group of patients. Thus, other mutations in the
LDLR gene might require other running conditions to be detected.

It is also important to note that different running conditions should be used for different exons. For genes other than the LDLR gene, where the optimal running conditions for each exon have not been established, our data might indicate that for screening purposes $15 \mathrm{~W}$ alone or combined with $50 \mathrm{~W}$ will detect the vast majority of the mutations. If the objective of the study is to identify $100 \%$ of the mutations, several different conditions should be used. However, in that case, direct DNA sequencing of individual exons might be an alternative strategy.

\section{ACKNOWLEDGMENTS}

This work was supported by grants from The Fridtjof Nansen Foundation for the Advancement of Science, The Norwegian Research Council on Cardiovascular Diseases, Merck Sharp and Dohme, Norway, and The Norwegian Research Council for Science and the Humanities.

\section{REFERENCES}

1. Orita, M., H. Iwahana, H. Kanazawa, K. Hayashi, and T. Sekiya. 1989. Detection of polymorphisms of human DNA by gel electrophoresis as single-strand conformation polymorphisms. Proc. Natl. Acad. Sci. 86: 2766-2770.

2. Orita, M., Y. Suzuki, T. Sekiya, and K. Hayashi. 1989. Rapid and sensitive detection of point mutations and DNA polymorphisms using the polymerase chain reaction. Genomics 5: 874-879.

3. Hayashi, K. 1991. PCR-SSCP: A simple and sensitive method for detection of mutations in the genomic DNA. PCR Methods Applic. 1: 34-38.

4. Spinardi, L., R. Mazars, and C. Theillet. 1991. Protocols for an improved detection of point mutations by SSCP. Nucleic Acids Res. 19: 4009

5. Goldstein, J.L., and M.S. Brown. 1989. Familial hypercholesterolemia. In The metabolic basis of inherited disease (ed. C.R. Scriver, A.L. Baudet, W.S. Sly, and D. Valle), pp. 1215-1250. McGraw-Hill, New York.

6. Yamamoto, T., C.G. Davis, M.S. Brown W.J. Schneider, M.L. Casey, J.L. Goldstein, and D.W. Russell. 1984. The human LDL receptor: A cysteine-rich protein with multiple Alu sequences in its m-RNA. Cell 39: 27-38.

7. Südhof, T.C., J.L. Goldstein, M.S. Brown, and D.W. Russell. 1985. The LDL receptor gene: A mosaic of exons shared with different proteins. Science 228: 815-822.

8. Rødningen, O.K., T.P. Leren, O. Røsby, S. Tonstad, L. Ose, and K. Berg. 1993. Haplotype analysis at the low density lipoprotein receptor locus in normal and familial hypercholesterolemia Norwegian subjects. Clin. Genet. 44: 214-220.

9. Soria, L.F., E.H. Ludwig, H.R.G. Clarke, G.L. Vega, S.M. Grundy, and B.J. McCarthy. 1989. Association between a specific apolipoprotein B mutation and familial defective apolipoprotein B-100. Proc. Natl. Acad. Sci. 86: 587-591.

10. Hansen, P.S., N. Rüdiger, A. TybjaergHansen, O. Faergeman, and N. Gregersen. 1991. Detection of the apoB-3500 mutation (glutamine for arginine) by gene amplification and cleavage with MspI. $J$. Lipid Res. 32: 1229-1233.

11. Leitersdorf, E., E.J. Tobin, J. Davignon, and H.H. Hobbs. 1990. Common lowdensity lipoprotein receptor mutations in the French Canadian population. J. Clin. Invest. 85: 1014-1023.

12. Kotze, M.J., A.E. Retief, P.A. Brink, and H.F.H. Welch. 1986. A DNA polymorphism in the human low-density lipoprotein receptor gene. S. Afr. Med. J. 70: 7779.

13. Hobbs, H.H., V. Esser, and D.W. Russell. 1987. AvalI polymorphism in the human LDL receptor gene. Nucleic Acids Res. 15: 379.

14. King-Underwood, L., V. Gudnason, S. Humphries, M. Seed, D. Patel, B. Knight, and A. Soutar. 1991. Identification of the proline to leucine mutation in the low density lipoprotein receptor in four unrelated patients with familial hypercholesterolemia in the UK. Clin. Genet. 40: 1728.

15. Michaud, J., L.C. Brody, G. Steel, G. Fontaine, L.S. Martin, D. Valle, and G. Mitchell. 1992. Strand-separating conformational polymorphism analysis: Efficacy of detection of point mutations in the human $\delta$-aminotransferase gene. Genomics 13: $389-394$.

Received July 8, 1993; accepted in revised form October 18, 1993. 




\section{Evaluation of running conditions for SSCP analysis: application of SSCP for detection of point mutations in the LDL receptor gene.}

T P Leren, K Solberg, O K Rødningen, et al.

Genome Res. 1993 3: 159-162

References This article cites 14 articles, 4 of which can be accessed free at: http://genome.cshlp.org/content/3/3/159.full.html\#ref-list-1

License

Email Alerting

Receive free email alerts when new articles cite this article - sign up in the box at the Service top right corner of the article or click here.

\section{Affordable, Accurate Sequencing.}

To subscribe to Genome Research go to: https://genome.cshlp.org/subscriptions 